\title{
PENGEMBANGAN MEDIA LAGU RUMUS MATEMATIKA BERBASIS AUDIO PLAYER UNTUK KELAS VI SD/SEDERAJAT
}

\author{
Ama Gusti Azis ${ }^{1}$, Indra Martha Rusmana ${ }^{2}$ \\ ${ }^{1}$ MAN 4 Jakarta, ${ }^{2}$ Universitas Indraprasta PGRI \\ amaiarranger@gmail.com ${ }^{1}$,indramartharusmana@ymail.com ${ }^{2}$
}

\begin{abstract}
This study aims to determine the feasibility of using the mathematical formula song media in the material volume of space for class VI SD / equivalent. The method used in this study is the Research and Development method using ADDIE development procedures, namely (Analysis, Design, Development, Implementation, and Evaluation). The data collection method used an expert test validation questionnaire. The results of data analysis in the media validation process included media experts, namely 4.06 meaning "good", material experts namely 4.53 meaning "very good" and linguists namely 3.97 meaning "good". It can be concluded that the average feasibility of the mathematical formula song media is feasible because the average results are good. This research was conducted at MI Nurul Ikhlas Depok and was carried out until expert testing, namely classroom teachers, and no small field tests were carried out on students due to the Covid-19 pandemic in 2020.
\end{abstract}

Keywords: ADDIE Model, Media Song Formula, Volume Build Space

\begin{abstract}
Abstrak
Penelitian ini bertujuan untuk mengetahui kelayakan penggunaan media lagu rumus matematika pada materi volume bangun ruang untuk kelas VI SD/Sederajat. Metode yang digunakan penelitian ini adalah metode Research and Development (Penelitian Pengembangan) dengan menggunakan prosedur pengembangan ADDIE yaitu (Analysis, Design, Development, Implementation, and Evaluation). Metode pengambilan data menggunakan angket validasi uji pakar. Hasil analisis data dalam proses validasi media diantaranya dari ahli media yaitu 4,06 berarti "baik", ahli materi yaitu 4,53 berarti "sangat baik" dan ahli bahasa yaitu 3,97 berarti "baik". Dapat disimpulkan bahwa rata-rata kelayakan media lagu rumus matematika adalah layak karena rata-rata menunjukkan hasilnya adalah baik. Penelitian ini dilaksanakan di MI Nurul Ikhlas Depok dan dilakukan sampai uji pakar yaitu guru kelas dan tidak dilakukan uji lapangan kecil terhadap siswa karena pandemi Covid-19 tahun 2020.
\end{abstract}

Kata kunci: Model ADDIE , Media Lagu Rumus, Volume Bangun Ruang 


\section{PENDAHULUAN}

Pendidikan itu memanusiakan manusia, yaitu proses seseorang untuk mengembangkan potensi dalam bentuk tingkah laku, sosial, pengetahuan dan keterampilan. Pendidikan juga merupakan suatu perubahan terhadap masa depan dan kesehjateraan hidup yang berkualitas serta terciptanya generasi bangsa yang mampu menjadi penggerak kehidupan. Manusia dapat mengembangkan potensinya melalui pendidikan beriringan dengan kemajuan ilmu pengetahuan dan teknologi saat ini.

Pendidikan juga memiliki masalah yang cukup besar dan perlu kita pahami bersama. Menurut (Astuti \& Leonard, 2015:103) bahwa masalah pendidikan yaitu rendahnya mutu pendidikan di Indonesia dikarenakan pengajaran yang disajikan tidak menarik dan itu sangat berpengaruh terhadap hasil pembelajaran di dalam kelas. Dunia yang semakin lama terus berkembang sudah sepatutnya guru melakukan perubahan cara mengajar, agar pembelajaran begitu menyenangkan dan efektif. Hasil studi PISA 2018 dari kemendikbud yang dirilis oleh OECD (Organization for Economic Co-operation and Development) bahwa "Mencari, mengevaluasi, dan merefleksi informasi, siswa Indonesia lebih pandai dibandingkan dalam memahami infromasi tersebut”. Maka dari itu, peran pemerintah dan masyarakat adalah elemen penting memajukan pendidikan menjadi lebih baik dan terarah.

Pendidikan yang bersifat intelek salah satunya adalah pendidikan matematika. Menurut (Leonard, 2013:78) bahwa "Ilmu universal adalah matematika, yang memiliki peranan penting dalam berbagai disiplin ilmu, mengembangkan daya pikir manusia dan didasari oleh perkembangan teknologi modern”. Sampai saat ini, pendidikan matematika masih menjadi problematika dan sulit dalam pembelajaran yang dilakukan oleh peserta didik. Matematika menjadi salah satu sorotan yang harus di benahi dari segi strategi mengajar guru, metode yang digunakan, sistem kurikulum pendidikan yang harus di upgrade pola kerjanya, dan kualitas dari pendidikan itu sendiri.

Kurangnya kualitas mengajar guru disebabkan kemampuan pembuatan dan penggunaan media pembelajaran yang sangat rendah. Peserta didik kesulitan untuk berkonsentrasi dan kurangnya minat untuk belajar ini dikarenakan tidak menariknya sebuah media pembelajaran yang digunakan. Hal tersebut mengakibatkan rendahnya pula tingkat pemahaman peserta didik. Berkembangnya ilmu pengetahuan dan teknologi, penggunaan 
Jurnal Lebesgue : Jurnal Ilmiah Pendidikan Matematika, Matematika dan Statistika

Ama Gusti Azis, Indra Martha Rusmana

Volume 1, No. 3, Desember 2020 hal.140-152

DOI Artikel : 10.46306/lb.v1i3.28

media sangat berperan penting untuk mendukung proses kegiatan pembelajaran. Menurut Sadiman, dkk. (dalam Nurdiyati, 2016:443) mengungkapkan bahwa media adalah alat bantu berupa pesan yang disalurkan dari pengirim ke penerima yang dapat merangsang pikiran, perasaan, perhatian dan minat siswa sehingga proses belajar menjadi lebih nyata.

Berdasarkan hasil penelitian sebelumnya, menurut (Fita, Cahyadi, \& Budiningtyas, 2017:95) bahwa suasana hati dan konsentrasi peserta didik dalam menerima pembelajaran dapat ditingkatkan melalui proses pembelajaran dengan penggunaan media lagu. Oleh karena itu, pelajaran tidak akan terhambat karena terbukti bahwa alunan suara lagu mempengaruhi suasana dan menghilangkan rasa tegang dalam belajar sehingga proses pembelajaran lebih menyenangkan bagi peserta didik.

Menurut (Fita, Cahyadi, \& Budiningtyas, 2017:104) juga bahwa solusi dalam menciptakan variasi pembelajaran matematika adalah dengan media lagu rumus matematika yang dikembangkan, dibuat dengan cara menyesuaikan lirik lagu dengan materi pembelajaran dan memodifikasinya dengan lagu anak-anak. Media lagu rumus matematika yang diciptakan oleh peneliti saat ini adalah tidak menggunakan lagu anak-anak, karena zaman sudah berubah menjadi serba modern. Perbandingan antara lagu anak-anak dan lagu yang diciptakan oleh peneliti adalah penyajian dan instrumen musiknya.

Faktanya, pada pembelajaran matematika kelas VI di Madrasah Ibtidaiyah (MI) Nurul Ikhlas Depok bahwa matematika dipandang sebagai mata pelajaran yang sulit dan kurang menarik bagi peserta didik. Penggunaan media pembelajaran belum maksimal dilakukan sehingga permasalahan ini terjadi.

"Dalam pembelajaran di kelas, saya menggunakan metode ceramah dan memanfaatkan buku paket/lks. Terbatasnya kemampuan saya dalam membuat media pembelajaran sehingga pembelajaran menjadi kurang menarik. Media pembelajaran yang menarik pasti akan membuat peserta didik menjadi bersemangat dan tertarik untuk belajar.” Ujar Bu Lasmawati.

Peneliti melakukan wawancara oleh guru kelas VI MI Nurul Ikhlas diperoleh bahwa (1) Media pembelajaran yang menarik belum digunakan sehingga peserta didik merasa bosan, (2) Guru tidak memiliki kemampuan untuk membuat sebuah media pembelajaran terutama dengan media lagu atau audio, (3) Media pendidikan berupa lagu atau audio 
Jurnal Lebesgue : Jurnal Ilmiah Pendidikan Matematika, Matematika dan Statistika

Ama Gusti Azis, Indra Martha Rusmana

Volume 1, No. 3, Desember 2020 hal.140-152

DOI Artikel : 10.46306/lb.v1i3.28

terbatas jumlahnya, (4) Selera musik peserta didik sekarang telah menjadi kehidupan seharihari. Permasalahan ini tentu menjadi pusat perhatian dan memberikan motivasi kepada guru dan peserta didik, karena akan berpengaruh terhadap perkembangannya terutama dalam proses pembelajaran.

Output dari media peneliti ini berbasis Audio Player (MP3) dalam bentuk format CD (Compact Disk) atau Flash Disk. Menurut M. Azwar (dalam Nurhayata, 2015:489) bahwa Flash disk adalah memory eksternal untuk menyimpan informasi file audio yang berbasis MP3 player. Menurut (Zeng, 2011:98) bahwa fungsi asli pemutar MP3 sebagai perangkat musik portal, selain itu juga sebagai perangkat penyimpanan yang nyaman oleh para pengguna untuk mengakses konten audio dan video yang dipersonalisasi seperti podcast acara TV, berita, dan materi kursus. Oleh karena itu, penelitian pengembangan ini bertujuan untuk mendesain dan mengembangkan media pembelajaran berupa media lagu berbasis audio player untuk peserta didik kelas VI SD/Sederajat pada materi Volume Bangun Ruang dan matematika menjadi pelajaran yang menarik.

\section{METODE PENELITIAN}

Metode yang digunakan peneliti adalah penelitian pengembangan (Research and Development). Prosedur penelitian dan pengembangan ini menggunakan model ADDIE yang melibatkan lima tahapan, yaitu: Analysis (Analisis), Design (Perencanaan), Development (Pengembangan), Implementation (Penerapan), dan Evaluation (Evaluasi). Menurut (Kurniati, Prahmana, Makur, \& Jelatu, 2018:163) bahwa proses pembelajaran yang sistematis, efektif, dan inovatif dapat dikembangkan melalui proses tahapan model ADDIE.

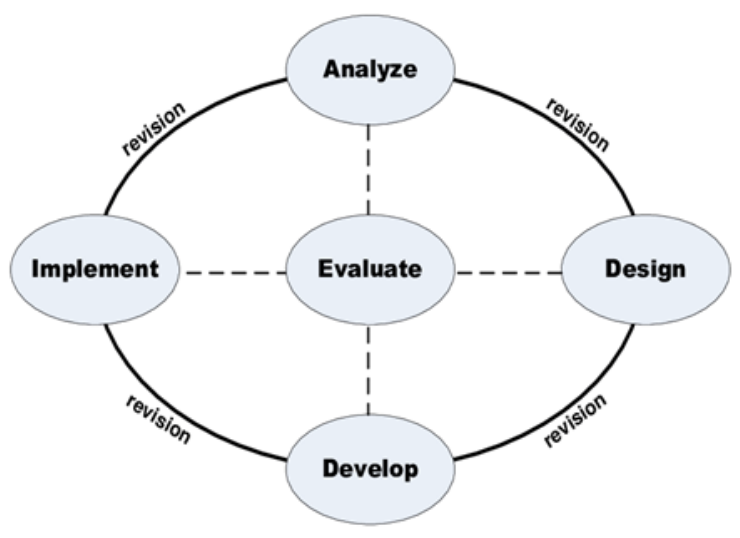

Gambar 1. Model ADDIE

Adapun jenis data yang akan digunakan dalam penelitian ini terdiri dari dua data, yaitu: 
a) Data kualitatif merupakan data mengenai proses pengembangan media pembelajaran berupa kritik dan saran dari ahli materi, ahli media dan bahasa.

b) Data kuantitatif merupakan data pokok penelitian yang berupa data penilaian tentang media pembelajaran dari ahli materi, ahli media dan bahasa.

Peneliti mengambil metode pengumpulan data menggunakan angket untuk mendapatkan data mengenai kelayakan media lagu rumus ini sebagai media pembelajaran matematika. Menurut (Mustari \& Rahman, 2012:45) Angket digunakan sebagai daftar isian untuk merekam observasi atas tingkah laku responden, atau sebagai pertanyaan wawancara, atau sebagai ujian nota-tulis, dan sebagainya. Angket yang digunakan meliputi angket validasi media lagu rumus berbasis audio player untuk ahli materi, ahli media, dan ahli bahasa. Angket penilaian pada media ini memiliki indikator dari beberapa aspek yang tersusun dan masing-masing indikator memiliki jumlah yang berbeda. Validasi instrumen ini menghasilkan angket yang siap digunakan dalam data penelitian. Berikut ini adalah kisi kisi instrumen angket validasi media lagu rumus matematika berbasis audio player, yaitu :

\section{Angket Media untuk Ahli Materi}

Ahli materi akan mengevaluasi media lagu rumus matematika berdasarkan aspek isi, kebahasaan, dan kemudahan penggunaan. Sebelum tahap implementasi, angket media lagu rumus matematika ini digunakan untuk penilaian, memperoleh tanggapan dan menjadi bahan evaluasi apakah media pembelajaran ini layak ujicoba atau tidak dari ahli materi. Angket ini terdiri dari 14 butir pernyataan dengan kisi-kisi instrumen yang disajikan pada tabel berikut :

Tabel 1. Kisi-Kisi Instrumen Angket Validasi Ahli Materi

\begin{tabular}{lcl}
\hline No & Aspek & \multicolumn{1}{c}{ Indikator } \\
\hline 1. & Isi & $\begin{array}{l}\text { a. Kejelasan Konsep dan Komponen Materi } \\
\text { b. Kesesuaian dengan Karakteristik siswa }\end{array}$ \\
\hline 2. & Kebahasaan & a. Penggunaan Lirik Lagu \\
\hline 3. & Kemudahan Penggunaan & a. Keefektifan dan keefesiensian media lagu \\
\hline
\end{tabular}

\section{Angket Media untuk Ahli Media}

Ahli media akan mengevaluasi media lagu rumus matematika berdasarkan aspek isi, kebahasaan, dan penyajian. Sebelum tahap implementasi, angket media lagu rumus matematika ini digunakan untuk penilaian, memperoleh tanggapan dan menjadi bahan evaluasi apakah media pembelajaran ini layak ujicoba atau tidak dari ahli media. Angket ini terdiri dari 12 butir peryataan dengan kisi-kisi instrumen yang disajikan pada tabel berikut: 
Jurnal Lebesgue : Jurnal Ilmiah Pendidikan Matematika, Matematika dan Statistika

Ama Gusti Azis, Indra Martha Rusmana

Volume 1, No. 3, Desember 2020 hal.140-152

DOI Artikel : 10.46306/lb.v1i3.28

Tabel 2. Kisi-Kisi Instrumen Angket Validasi Ahli Media

\begin{tabular}{|c|c|c|}
\hline No & Aspek & Indikator \\
\hline 1. & Isi & $\begin{array}{l}\text { a. Kejelasan konsep dan materi } \\
\text { b. Kesesuaian dengan perkembangan usia }\end{array}$ \\
\hline 2. & Kebahasaan & a. Kualitas Lirik dalam lagu \\
\hline 3. & Penyajian & $\begin{array}{l}\text { a. Kualitas Media Lagu } \\
\text { b. Kemudahan Penggunaan }\end{array}$ \\
\hline
\end{tabular}

\section{Angket Media untuk Ahli Bahasa}

Ahli bahasa akan mengevaluasi media lagu rumus matematika berdasarkan aspek kebahasaan, interaktif dan komunikatif. Sebelum tahap implementasi, angket media lagu rumus matematika ini digunakan untuk penilaian, memperoleh tanggapan dan menjadi bahan evaluasi apakah media pembelajaran ini layak ujicoba atau tidak dari ahli bahasa. Angket ini terdiri dari 10 butir peryataan dengan kisi-kisi instrumen yang disajikan pada tabel berikut:

Tabel 3. Kisi-Kisi Instrumen Angket Validasi Ahli Bahasa

\begin{tabular}{ccl}
\hline No & \multicolumn{1}{c}{ Aspek } & \multicolumn{1}{c}{ Indikator } \\
\hline 1. & Kebahasaan & a. Kesesuaian dengan Kaidah Bahasa \\
\hline 2. & Interaktif & a. Kesesuaian dengan Karakter Peserta Didik \\
\hline 3. & Komunikatif & a. Pemahaman pesan \\
\hline
\end{tabular}

Peneliti menggunakan Skala Likert untuk menjawab alternatif pernyataan yang dipilih oleh responden. Menurut Likert (dalam Budiaji, 2013:128) bahwa "jawaban butir pernyataan berupa sangat setuju, setuju, tidak memutuskan, tidak setuju, dan sangat tidak setuju untuk mengukur perilaku individu dengan merespon ke 5 titik pilihan tersebut yang digunakan oleh Skala Likert”. Responden diberikan alternatif jawaban pada setiap pernyataan dengan skor sebagai berikut :

Tabel 4. Pedoman Skor Skala Likert

\begin{tabular}{lc}
\hline \multicolumn{1}{c}{ KETERANGAN } & SKOR \\
\hline Sangat Baik $(\mathrm{SB})$ & 5 \\
\hline Baik $(\mathrm{B})$ & 4 \\
\hline Cukup $(\mathrm{C})$ & 3 \\
\hline Kurang $(\mathrm{K})$ & 2 \\
\hline Sangat Kurang (SK) & 1 \\
\hline
\end{tabular}


Kriteria kelayakan pada media lagu rumus matematika berbasis audio player ini sangat diperlukan teknik analisis data. Adapun langkah-langkah dalam menganalisis kriteria "layak" pada media yang dikembangkan adalah sebagai berikut:

$$
X=\frac{\sum x}{n}
$$

$$
\text { Keterangan : } \quad \begin{aligned}
X & =\text { skor rata-rata } \\
\sum x & =\text { jumlah skor } \\
n & =\text { jumlah butir }
\end{aligned}
$$

Sesuai paduan dalam mengkonversi data, maka peneliti mengkonversi data kuantitatif menjadi data kualitatif adalah sebagai berikut :

Tabel 5. Konversi Data Kuantitatif Ke Data Kualitatif Berskala 5

\begin{tabular}{ccc}
\hline Rumus & Rerata Skor & Klasifikasi \\
\hline$X>\bar{X}_{i}+1,8 \times s b_{i}$ & $>4,2$ & Sangat Baik \\
\hline $\bar{X}_{i}+0,60 \times s b_{i}<X \leq \bar{X}_{i}+1,8 \times s b_{i}$ & $>3,4-4,2$ & Baik \\
\hline $\bar{X}_{i}-0,60 \times s b_{i}<X \leq \bar{X}_{i}+0,6 \times s b_{i}$ & $>2,6-3,4$ & Cukup \\
\hline $\bar{X}_{i}-0,60 \times s b_{i}<X \leq \bar{X}_{i}-0,6 \times s b_{i}$ & $>1,8-2,6$ & Kurang \\
\hline$X \leq \bar{X}_{i}-1,8 \times s b_{i}$ & $\leq 1,8$ & Sangat \\
\hline
\end{tabular}

Keterangan :

$$
\begin{aligned}
X & =\text { skor empiris } \\
\bar{X}_{i} & =\text { rerata ideal } \\
& =\frac{1}{2} \times(\text { skor maksimum ideal }+ \text { skor minimal ideal }) \\
s b_{i} & =\text { simpangan baku ideal } \\
& =\frac{1}{6} \times(\text { skor maksimum ideal }- \text { skor minimum ideal })
\end{aligned}
$$

Dalam penelitian ini, media yang dikembangkan dianggap layak apabila hasil analisis data memperoleh rerata skor lebih dari 3,4 - 4,2 yang berarti "baik" pada semua aspek, begitu juga media belum layak digunakan apabila hasil analisis data memperoleh rerata skor = $2,6<\mathrm{X} \leq 3,4$ yang berarti "cukup" pada semua aspek maka media tersebut perlu adanya perbaikan. 
Jurnal Lebesgue : Jurnal Ilmiah Pendidikan Matematika, Matematika dan Statistika

Ama Gusti Azis, Indra Martha Rusmana

Volume 1, No. 3, Desember 2020 hal.140-152

DOI Artikel : $10.46306 /$ lb.v1i3.28

\section{HASIL DAN PEMBAHASAN}

Hasil penelitian pengembangan media pembelajaran yang menggunakan model ADDIE, sesuai dengan langkah-langkah sebagai berikut:

\section{Analysis (Analisis)}

Berdasarkan hasil wawancara dengan guru kelas MI Nurul Ikhlas diperoleh hasil bahwa : Pertama, Media pembelajaran yang menarik belum digunakan sehingga peserta didik merasa bosan. Kedua, Guru tidak memiliki kemampuan untuk membuat sebuah media pembelajaran terutama dengan media lagu atau audio. Ketiga, Media pendidikan berupa lagu atau audio terbatas jumlahnya. Keempat, Selera musik peserta didik sekarang telah menjadi kehidupan sehari-hari. Hal ini disebabkan oleh minat siswa untuk belajar matematika sangat rendah, fasilitas di sekolah juga sangat minim, guru kesulitan menjelaskan materi yang menarik untuk siswa. Oleh karena itu, tentu menjadi pusat perhatian dan memberikan motivasi kepada guru dan peserta didik dengan cara memberikan media yang dibuat oleh peneliti untuk membantu keberlangsungan kegiatan belajar dan mengajar.

\section{Design (Perencanaan)}

Hasil analisis yang diperoleh, dituangkan pada media lagu rumus matematika. Rancangan media lagu rumus matematika ini disesuaikan dengan tinjauan materi pada pokok bahasan volume bangun ruang yang merupakan suatu perencanaan peneliti untuk mencapai tujuan siswa dalam menggunakan media lagu ini. Adapun tahap yang dilakukan dalam perencanaan ini adalah sebagai berikut :

a. Berdasarkan analisis kebutuhan, media lagu ini melalui tahap proses tinjauan materi yang akan dijadikan bahan dalam pembuatan media dan rumus yang akan dikembangkan menjadi sebuah nada atau lagu.

b. Peralatan yang digunakan dalam pembuatan media lagu ini ialah laptop, pena, paper, dan Guitar. Sound Recorder digunakan untuk membuat rekaman media lagu. Lirik lagu yang dirancang untuk dituangkan pada media lagu adalah :

\section{VOLUME BANGUN RUANG}

Song 1 :

Hey...kalian semua

Kawan-kawan semua

Mari kita belajar matematika

Belajar Volume Bangun Ruang 
Jurnal Lebesgue : Jurnal Ilmiah Pendidikan Matematika, Matematika dan Statistika

Ama Gusti Azis, Indra Martha Rusmana

Volume 1, No. 3, Desember 2020 hal.140-152

DOI Artikel : 10.46306/lb.v1i3.28

\section{Reff 1 :}

Rumus Balok, Panjang kali lebar dikali tinggi $(p \times l \times t)$

Ada Kubus, Sisi kali sisi di kali sisi $(s \times s \times s)$

Prisma segitiga volumenya, Luas alas di kali tinggi (Luas Alas $\times t$ )

Ada Limas segi empat $\left(\frac{1}{3} \times p \times l \times t\right)$

Song 2:

Hey.. kamu semua

Yuk bersiap lagi

Kita Belajar matematika

Rumus Volume Bangun Ruang

Reff 2 :

Rumus Tabung, Phi kali $r$ kuadrat dikali tinggi $\left(\pi \times r^{2} \times t\right)$

Bola volumenya $\left(\frac{4}{3} \times \pi \times r^{3}\right)$

Ada satu bangun ruang lagi

Ayo siapa yang bisa tebak?

Ada bangun ruang Kerucut $\left(\frac{1}{3} \times \pi \times r^{2} \times t\right)$

\section{Development (Pengembangan)}

\section{a. Pembuatan lagu kedalam template software}

Software yang digunakan dalam pembuatan lagu ini adalah FL Studio. FL Studio ini di aplikasikan dalam laptop dan menggunakan soundsystem, perangkat alat musik dan mic condensor yang memadai.

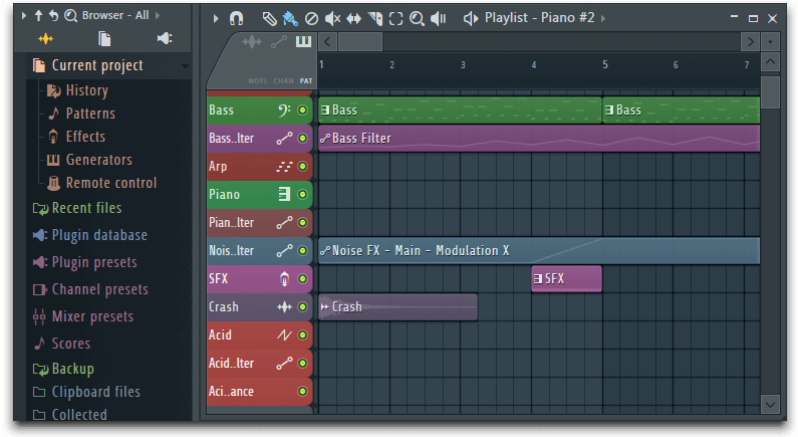

Gambar 2. FL STUDIO 
Jurnal Lebesgue : Jurnal Ilmiah Pendidikan Matematika, Matematika dan Statistika

Ama Gusti Azis, Indra Martha Rusmana

Volume 1, No. 3, Desember 2020 hal.140-152

DOI Artikel : 10.46306/lb.v1i3.28

\section{b. Validasi Ahli Media, Ahli Materi dan Ahli Bahasa}

Sebelum melakukan kegiatan uji coba, kelayakan sebuah media dilakukan proses validasi. Ahli media, ahli materi, dan ahli bahasa akan melakukan penilaian dan memberikan kritik serta saran untuk memaksimalkan media pembelajaran. Hasil penilaian, kritik, dan saran ahli digunakan sebagai acuan utama dalam memperbaiki media tahap awal sebelum diuji lapangan. Hasil validasi ahli media, ahli materi, dan ahli bahasa adalah sebagai berikut :

Tabel 6. Rata-Rata Hasil Validasi Ahli Media

\begin{tabular}{ccc}
\hline Validator & Rata-Rata & Kriteria \\
\hline Ahli Media & 4,06 & Baik \\
\hline
\end{tabular}

Hasil rata-rata pada tabel di atas, maka hasil validasi ahli media dalam kategori "baik" dengan rata-rata penilaian terhadap media yaitu 4,06.

Tabel 7. Rata-Rata Hasil Validasi Ahli Materi

\begin{tabular}{ccc}
\hline Validator & Rata-Rata & Kriteria \\
\hline Ahli Materi 1 & 4,41 & Sangat Baik \\
\hline Ahli Materi 2 & 4,66 & Sangat Baik \\
\hline
\end{tabular}

Hasil rata-rata pada tabel di atas, maka hasil validasi ahli materi dalam kategori "sangat baik" dengan rata-rata penilaian terhadap media yaitu 4,53.

Tabel 8. Rata-Rata Hasil Validasi Ahli Bahasa

\begin{tabular}{ccc}
\hline Validator & Rata-Rata & Kriteria \\
\hline Ahli Bahasa 1 & 3,7 & Baik \\
\hline Ahli Bahasa 2 & 4,55 & Sangat Baik \\
\hline
\end{tabular}

Hasil rata-rata pada tabel di atas, maka hasil validasi ahli bahasa dalam kategori "baik" dengan rata-rata penilaian terhadap media yaitu 3,97.

\section{Implementation (Penerapan)}

Penerapan media pembelajaran ini hanya dibatasi sampai uji pakar yaitu ahli media, materi, dan bahasa. Setelah media lagu ini dinyatakan layak untuk diproduksi yang telah di validasi oleh ahli media, ahli materi dan ahli bahasa, lalu media ini tidak diujikan pada uji lapangan pada kelompok kecil, dikarenakan kurangnya akses penelitian pada saat pandemi 
Jurnal Lebesgue : Jurnal Ilmiah Pendidikan Matematika, Matematika dan Statistika

Ama Gusti Azis, Indra Martha Rusmana

Volume 1, No. 3, Desember 2020 hal.140-152

DOI Artikel : 10.46306/lb.v1i3.28

Covid 19 2020. Kekurangan dan kelemahan pada media lagu rumus yang telah jadi ini bertujuan untuk melihat keefektifan lagu bila digunakan oleh peserta didik yang sudah tervalidasi oleh para ahli.

\section{Evaluation (Penilaian)}

Evaluasi media lagu rumus matematika berbasis audio player yang telah dikembangkan ini adalah tahap terakhir yang dilakukan oleh peneliti dalam model pengembangan ADDIE. Media yang dihasilkan dalam hal ini adalah media lagu rumus matematika berbasis audio player pada materi volume bangun ruang kelas VI SD/Sederajat untuk diketahui apakah media ini layak atau tidak sebagai media pembelajaran. Setelah melalui tahap penerapan, kemudian para ahli sebagai aspek pengguna menilai kelayakan media dengan diberikannya angket validasi. Setelah proses tahapan uji coba dan penilaian, para ahli memberikan tanggapannya terhadap media yang siap digunakan oleh para guru dan peserta didik. Berikut adalah tanggapan yang diberikan oleh para ahli, antara lain :

a. Media lagu rumus adalah ide cemerlang;

b. Media ini akan membantu proses pembelajaran;

c. Media ini akan mudah dihafal;

d. Media lagu rumus harus dikembangkan lebih baik lagi;

e. Penekanan pada irama lagu diperbaiki secara sempurna agar tepat sasaran.

Penelitian pengembangan ini adalah penelitian pada media lagu rumus matematika berbasis audio player pada materi volume bangun ruang untuk kelas VI SD/Sederajat. Media ini berbentuk lagu yang bernuansa Pop Riang, sehingga dapat melatih kemandirian siswa dalam belajar matematika yang lebih menyenangkan. Menurut (Vina, Ramlah, \&Utami, 2018:162) bahwa "agar tidak membosankan, media lagu dapat membantu peserta didik dalam proses pembelajaran di dalam kelas". Peneliti menyadari bahwa proses penelitian dan pengembangan media lagu rumus pembelajaran matematika ini tidaklah sempurna, perlu adanya perbaikan di masa yang akan datang. Adapun keterbatasan dari penelitian ini antara lain:

1. Keterbatasan dari segi teknis pembuatan media yang masih belum memenuhi standar minimal untuk pembuatannya sehingga media yang dikembangkan belum maksimal. Keterbatasan waktu, dana yang tersedia, dan kondisi pandemi Covid 19 sangat berpengaruh kepada kemampuan peneliti dalam melakukan tatap muka secara langsung dengan pihak rekaman atau studio. 
2. Keterbatasan uji lapangan kecil terhadap siswa yang masih menjadi suatu masalah ketika sekolah dilakukan pembelajaran di rumah pada saat pandemi covid 19 sehingga kurangnya akses penelitian secara langsung.

\section{KESIMPULAN}

Media lagu pembelajaran yang sesuai dengan kemajuan teknologi, diharapkan untuk mengurangi kejenuhan siswa dalam memahami pelajaran. Guru juga harus memiliki semangat dan motivasi diri karena melihat begitu pentingnya peran media dalam proses pembelajaran. Berdasarkan hasil penelitian pengembangan media lagu rumus matematika pada materi volume bangun ruang berbasis audio player untuk kelas VI SD/Sederajat melalui proses validasi oleh para ahli, dapat disimpulkan bahwa media lagu rumus matematika berbasis audio player ini dinyatakan "Layak" sebagai media pembelajaran. Hasil Penelitian dari para ahli bahwa di dalam aspek media dan bahasa mendapatkan kriteria "Baik" dan aspek materi mendapatkan kriteria "Sangat Baik" sebagai media pembelajaran.

Hasil validasi dan ujicoba kepada para ahli menunjukkan bahwa seorang guru atau dosen senang dan tertarik menggunakan media lagu berbasis audio player. Media lagu dapat membangkitkan suasana belajar sehingga pemahaman siswa akan lebih mudah dicapai terhadap materi rumus volume bangun ruang serta mempermudah siswa dalam belajar karena dapat dibawa kemanapun, dimanapun, dan kapanpun.

\section{DAFTAR PUSTAKA}

Astuti, A., \& Leonard. (2015). Peran kemampuan komunikasi matematika terhadap prestasi belajar matematika siswa. Formatif, 2(2), hlm.102-110. Retrieved from : http://dx.doi.org/10.30998/formatif.v2i2.91.

Budiaji, W. (2013). Skala pengukuran dan jumlah respon skala likert. Jurnal ilmu pertanian dan perikanan, 2(2), 127-133. Retrieved from : http://umbidharma.org/jipp.

Elawati, V. P., Ramlah, \& Utami, M. R. (2018). Optimalisasi fungsi otak kanan melalui media lagu terhadap pencapaian kemampuan komunikasi matematis siswa SMP. Prosiding Seminar Nasional Matematika dan Pendidikan Matematika (pp. 160-166. Retrieved from : http://journal.unsika.ac.id/index.php/sesiomadika). Jawa Barat: Sesiomadika. 
Fita, M., Cahyadi, F., \& Budiningtyas, A. K. (2017). Pengembangan media lagu matematika dalam pembelajaran di kelas V Sekolah Dasar. Jurnal UPI : Mimbar Sekolah Dasar, 4(1), 92-105. Retrieved from : https://doi.org/10.23819/mimbar-sd.v4i1.6145.

Kurniati, K., Prahmana, R. C., Makur, A. P., \& Jelatu, S. (2018). Math comics, vectors , and the strategy of preview, question, read, reflect, recite, review (PQ4R). Formatif : Jurnal Pendidikan MIPA, 8(3), 159-174. Retrieved from : http://dx.doi.org/10.30998/formatif.v8i3.2716 Math.

Leonard. (2015). EduResearch. Jakarta: Unindra Press.

Mustari, M., \& Rahman, M. (2012). Pengantar Metode Penelitian. Yogyakarta: LaksBang Pressindo.

Nurdiyati, S. (2016). Penerapan model pembelajaran terbimbing untuk meningkatkan hasil belajar matematika siswa kelas I SDN 010 Banjar Panjang Kecamatan Kerumutan. Primary: Jurnal Pendidikan Guru Sekolah Dasar, 5(3), 442-450. Retrieved from: https://primary.ejournal.unri.ac.id/index.php/JPFKIP/article/download/3930/3819.

Nurhayata, I. G. (2015). Pengembangan prototipe sistem kntrol MP3 player berbasis radio frequency identification pada sistem pelayanan informasi objek museum. Jurnal Sains dan Teknologi, 4(1), 487-502. Retrieved from : http://dx.doi.org/10.23887/jstundiksha.v4i1.4928.

Zeng, L. (2011). More than Audio on the Go : uses and gratifications of MP3 players. Communication Research Reports, 28(1), 97-108. Retrieved from : http://dx.doi.org/10.1080/08824096.2011.541367. 